\title{
INTERNATIONAL UNION OF PURE AND APPLIED CHEMISTRY
}

\author{
PHYSICAL CHEMISTRY DIVISION \\ COMMISSION ON MOLECULAR STRUCTURE AND \\ SPECTROSCOPY
}

\section{RECOMMENDATIONS FOR THE PRESENTATION OF NMR DATA FOR PUBLICATION IN CHEMICAL JOURNALS}

\author{
Adopted at Washington, DC, USA \\ during 21-23 July 1971
}




\section{COMMISSION ON MOLECULAR STRUCTURE AND SPECTROSCOPY广}

\section{RECOMMENDATIONS FOR THE PRESENTATION OF NMR DATA FOR PUBLICATION IN CHEMICAL JOURNALS}

The extensive use of nuclear magnetic resonance spectroscopy in chemical research makes it desirable to encourage the presentation of n.m.r. data in a uniform manner. Commission I.5 (Molecular Structure and Spectroscopy) therefore recommends that the following conventions should be followed in the graphical presentation of n.m.r. data in chemical journals.

\section{A. CONVENTIONS RELATING TO PROTON SPECTRA}

(1) The dimensionless scale factor for chemical shifts should be $10^{6}$, i.e. parts per million, for which p.p.m. is a convenient abbreviation.

(2) The unit for measured data should be hertz (cycles per second), for which $\mathrm{Hz}$ is the appropriate abbreviation, and the frequency scale should run in the same direction as the dimensionless scale.

(3) The unit for spin-spin coupling constants should be hertz (cycles per second).

(4) The graphical presentation of spectra should show the frequency decreasing to the right (applied field increasing to the right), absorption increasing upwards, and the standard sweep direction should be from high to low frequency (low to high field).

(5) Whenever possible the dimensionless scale should be tied to an internal reference, which should normally be tetramethylsilane. The proton resonance of tetramethylsilane should be taken as zero; if some other internal reference is used that reference, and the conversion shift used to convert the measured shifts to the tetramethylsilane reference scale, should be explicitly stated. The dimensionless scale should be defined as positive in the high frequency (low field) direction. The scale in parts per million based on zero for tetramethylsilane should be termed the $\delta$ scale. A shift measured on this scale should be given as, for example, $\delta=5.00$, not $\delta=5.00$ p.p.m. The symbol $\delta_{\mathbf{H}}$ may be used if there is ambiguity about the nucleus under investigation.

$\dagger$ Titular Members: R. N. Jones (Canada' (Chairman); A. R. H. Cole (Australia) (ViceChairman); F. A. Miller (USA) (Secretary); Members: M. A. Elyashevich (USSR), Th. Förster (Germany), A. Hadni (France), Y. Morino (Japan), N. Sheppard (UK); Associate Members: E. Fluck (Germany), E. R. Lippincott (USA), R. C. Lord (USA), S. Nagakura (Japan), J. Plivá (Czechoslovakia), Sir Harold Thompson (UK), D. W. Turner (UK), Advisory Counsellor: G. Herzberg (Canada); National Representative: T. Urbanski (Poland). 
(6) When the spectra are submitted for publication, additional information should include:

(a) The name of the solvent used.

(b) The concentration of the solute.

(c) The name and concentration of the internal reference.

(d) The name of the external reference if one is used. Water should not normally be so used because of the temperature dependence of its resonance.

(e) The temperature of the sample.

(f) The procedure used to measure the peak positions.

(g) The radio-frequency at which the measurements were made; alternatively the magnetic field should be stated if the spectrum was obtained by a frequency sweep method.

Other information should be added where appropriate or necessary, e.g. the sweep rate, the magnitude of the $H_{1}$ fields, data pertinent to the use of spin decoupling, and whether oxygen has been removed from the sample. Solvent and impurity bands, carbon-13 satellites, or spinning sidebands should be indicated as such.

If single resonances or part spectra are presented as diagrams there should be a graphical indication of the distance corresponding to a suitable range of $\mathrm{Hz}$ so that fine-structure spacings, or widths of broad resonances, can be estimated.

\section{B. CONVENTIONS RELATING TO SPECTRA FROM OTHER NUCLEI}

At this stage the Commission does not wish to make definite recommendations relating to n.m.r. spectra of other nuclei. However, increasing interest in the use of double resonance techniques to relate chemical shifts of other nuclei to the proton resonance of tetramethylsilane suggests that it may become advantageous to adopt the same conventions for other nuclei. 